\title{
Temperature effects on the dynamics of gonad and oocyte development in captive wild-caught blacklip (Haliotis rubra) and greenlip (H. laevigata) abalone
}

\author{
Mark A. Grubert ${ }^{1,2^{*}} \&$ Arthur J. Ritar ${ }^{1}$ \\ ${ }^{1}$ Marine Research Laboratories, Tasmanian Aquaculture and Fisheries Institute, \\ University of Tasmania, Nubeena Crescent, Taroona Tasmania 7053, Australia. \\ ${ }^{2}$ School of Aquaculture, Tasmanian Aquaculture and Fisheries Institute, University of \\ Tasmania, Locked Bag 1370, Launceston, Tasmania 7250, Australia.
}

\section{Summary}

Wild-caught blacklip (Haliotis rubra) and greenlip (H. laevigata) abalone were held from spent condition at $12^{\circ} \mathrm{C}, 14^{\circ} \mathrm{C}, 16^{\circ} \mathrm{C}$ or $18^{\circ} \mathrm{C}$ and routinely sampled to examine gonad development. Descriptors of gross structure included the Visual Gonad Index (VGI) and the Modified Gonad Bulk Index (MGBI). Oocyte Diameter Ratio (ODR) and oocyte volume (based on an ellipsoid) were used as descriptors of ovarian microstructure. For each species, the rate of increase in the VGI, MGBI and oocyte volume of animals held at different temperatures were used to estimate the Biological Zero Point (BZP), the critical temperature below which no development occurs. BZP estimates derived from the daily increase in VGI and oocyte volume were similar $\left(7.8^{\circ} \mathrm{C}\right.$ and $7.6^{\circ} \mathrm{C}$ for blacklip abalone; $6.9^{\circ} \mathrm{C}$ and $6.8^{\circ} \mathrm{C}$ for greenlip abalone, respectively), but those based on the increase in MGBI were up to $1.8^{\circ} \mathrm{C}$ lower $\left(6.0^{\circ} \mathrm{C}\right.$ and $5.7^{\circ} \mathrm{C}$, for blacklip and greenlip abalone, respectively). The mean MGBI, in terms of gonad volume per gram of shucked animal weight, ranged from $5-68 \mathrm{~mm}^{3} \mathrm{~g}^{-1}$ and $5-58 \mathrm{~mm}^{3} \mathrm{~g}^{-1}$ for blacklip and greenlip abalone, respectively. The ODR indicated that oocyte shape was highly variable in oocytes $<90 \mu \mathrm{m}$ diameter in both species. Above $90 \mu \mathrm{m}$, ODR values increased proportionally with oocyte size, indicating a transition in shape from elliptical to round. Ranges for mean oocyte volume for blacklip and greenlip abalone were $0.15-1.4 \times 10^{6} \mu \mathrm{m}^{3}$ and $0.02-1.83 \times 10^{6}$ $\mu \mathrm{m}^{3}$, respectively. The pattern of oocyte growth relative to temperature for both species is illustrated using tables of standardized residuals. Determination of the BZP for blacklip and greenlip abalone enables the calculation of the Effective Accumulative Temperature (EAT; the cumulative difference between the water temperature and the BZP, calculated daily) for gamete maturation of these species. This in turn facilitates predictive and deductive estimates of the completion of this process (when water temperature is known) in either natural or artificial (i.e. culture) environments.

Keywords: Biological zero point; Haliotis laevigata; Haliotis rubra; Modified gonad bulk index; Oocyte morphometrics; Temperature; Visual gonad index

\section{Introduction}

Blacklip (Haliotis rubra) and greenlip (H. laevigata) abalone are herbivorous marine gastropods inhabiting reefs and boulder fields in waters off southern Australia.

Commercial harvesting of these species began in the late 1960's and studies on their reproductive biology were initiated soon after (Harrison and Grant, 1971; Shepherd and Laws, 1974). Shepherd and Laws (1974) demonstrated that the reproductive cycle of these species in South Australia varied both annually and geographically, with varying degrees of seasonality in spawning. Subsequent studies on stocks from Victoria (McShane et al., 1986), Tasmania (L. Gurney, pers. comm.) and Western Australia (Wells and Mulvay, 
1992) have also reported seasonal peaks in spawning, but as yet no direct link between gonad development and environmental variables has been established in these species.

Kikuchi and Uki $(1974 a, b)$ first quantified the effect of temperature on sexual maturation of haliotids. They monitored the increase in the Visual Gonad Index (VGI) of $H$. discus hannai and $H$. discus discus at different water temperatures. The VGI is a noninvasive, semi-quantitative means of assessing gonad bulk in abalone and consists of four categories (0-3), describing successive changes in the size and shape of the gonad. At temperatures within the normal range for each species, there were positive linear relationships between the VGI (when the mean VGI $\leq 2.5$ ) and conditioning time. The rate of increase in VGI was proportional to water temperature, and when each value was plotted against water temperature, the zero value for VGI could be interpolated. This gave an estimate of the Biological Zero Point (BZP), the temperature below which gonad development is arrested. By subtracting the BZP from the daily water temperature and summing this figure over the conditioning time (in days), Kikuchi and Uki (1974a,b) were able to describe the Effective Accumulative Temperature (EAT, expressed as $\mathrm{EAT}^{\circ} \mathrm{C}$-days) for completion of gametogenesis and spawning. At present, there is only one account of the EAT for gamete maturation of southern hemisphere abalones (Kabir, 2001 for H. australis and $H$. iris).

Reproductive development in abalone may also be quantified by gonad indices and oocyte size. Gonad indices are based on cross-sectional measurements of the conical appendage (i.e. the gonad-digestive gland complex) and vary in their complexity and accuracy (see Hahn, 1989 for a review). The Modified Gonad Bulk Index (MGBI) of Tutschulte and Connell (1981) uses linear measurements from both the exterior and interior (i.e. the dimensions of each tissue in cross-section) of the conical appendage to produce the Estimate of Gonad Volume (EGV). The EGV is then divided by the shucked wet weight of the animal to yield the MGBI. Lleonart (1992) showed that the EGV could be derived using area rather than linear measurements. Furthermore, the formula given by Lleonart (1992) uses fewer terms than that of Tutschulte and Connell (1981) making it easier to compute.

Measurement of oocyte size as a means of describing reproductive development in marine organisms was first undertaken by Thompson (1915, cited by Clark, 1934). However, oocyte size frequency polygons are often difficult to interpret and are not amenable to significance testing. Grant and Tyler $(1983 a, b)$ reviewed the various means of describing and analyzing reproductive patterns in marine invertebrates. They promoted contingency table analysis as a means of determining statistically significant differences in oocyte size frequency data, and tables of standardized residuals to show the location of these differences, with positive residuals indicating a greater than expected frequency of oocytes in that size class, and negative residuals a lower than expected frequency of oocytes. The use of contingency table analysis and tables of standardized residuals has become common in studies dealing with changes in oocyte size (expressed as diameter, area or volume) frequency in abalone held under artificial (e.g. constant temperature) conditions (Lleonart, 1992; Hahn, 1994; Moss, 1998; Kabir, 2001). However, this method has only been used once for wild abalone (Kabir, 2001), despite the large number of studies on reproduction in wild haliotids.

The aim of this study was to first, describe gonad and oocyte development of blacklip and greenlip abalone held at four different temperatures $\left(12,14,16\right.$ or $\left.18^{\circ} \mathrm{C}\right)$ using several different indices (VGI, MGBI and oocyte size frequency) and second, to use the daily rate of change of these indices to calculate the BZP for gonad development of both species. Knowledge of BZP enables the calculation of the EAT for gamete maturation of these species (when the daily temperature and time interval are known). This allows 
comparisons of the gametogenic cycle between species, between wild and domesticated (i.e. cultured) stocks and also between populations with different thermal histories. An alternative means of calculating oocyte volume and an improved contingency table format is also presented.

\section{Methods}

\section{Collection and inspection of animals}

Blacklip and greenlip abalone were collected from West End, Settlement Point and Roydon Island (Furneaux group, north east Tasmania) on 23 November 2000 and 27 April 2001. Animals were transferred to the Tasmanian Aquaculture and Fisheries Institute, Marine Research Laboratories and held in $600 \mathrm{~L}$ tanks supplied with ambient temperature seawater until examination and allocation to experimental treatments. Prior to the start of the experiment (10 May 2001), animals were measured, weighed, tagged and VGI assessed according to the following criteria: $0=$ sex indistinguishable; $1=$ sex distinguishable, thin gonad with pointed tip; 2 = gonad partially enlarged with pointed tip; $3=$ gonad swollen with rounded tip. In both species, the size range for experimental animals was 100-130 mm shell length (SL). Blacklip abalone ranged from 143-334 g (mean $=218 \mathrm{~g}$ ) and greenlip abalone from $107-323 \mathrm{~g}($ mean $=210 \mathrm{~g})$. The majority of animals of both species had VGI scores of zero. Animals with VGI values of 2 or 3 were induced to spawn using heated UV-irradiated seawater (Grubert and Ritar, 2002). Only animals that spawned or had zero scores when first examined were used in the experiment. Of these, five to six animals of each sex and species were killed immediately post spawning and the gonad processed as detailed below. Animals generally appeared healthy, but the shells of some greenlips had small colonies of the spionid polychaete mudworm Boccardia knoxi.

\section{Experimental design}

Abalone of each sex and species were held in separate $150 \mathrm{~L}$ fibreglass tanks. Within each sex and species group, 36 animals were randomly assigned to each of four experimental temperatures $\left(12,14,16\right.$ or $\left.18^{\circ} \mathrm{C}\right)$ with two replicate tanks per temperature treatment $(2 \times 2 \times 4 \times 2=32$ tanks total $)$. The time interval for sampling was based on estimated BZP figures of $7.0^{\circ} \mathrm{C}$ for blacklip abalone and $8.0^{\circ} \mathrm{C}$ for greenlip abalone and an EAT interval of $400^{\circ} \mathrm{C}$-days for both species. For blacklip abalone, the number of days between each sampling ( $\mathrm{n}=$ the number of samplings at each temperature) were 80 days at $12^{\circ} \mathrm{C}(\mathrm{n}=3), 57$ days at $14^{\circ} \mathrm{C}(\mathrm{n}=4), 44$ days at $16^{\circ} \mathrm{C}(\mathrm{n}=6)$ and 36 days at $18^{\circ} \mathrm{C}(\mathrm{n}=6)$. Corresponding values for greenlip abalone were 100 days at $12^{\circ} \mathrm{C}(\mathrm{n}=3), 67$ days at $14^{\circ} \mathrm{C}$ $(\mathrm{n}=4), 50$ days at $16^{\circ} \mathrm{C}(\mathrm{n}=6)$ and 40 days at $18^{\circ} \mathrm{C}(\mathrm{n}=60)$. At these times, VGI was determined in 4-6 animals in each treatment group (selected at random from the duplicate tanks) and the mean VGI plotted against culture time for each temperature treatment. The slopes of these lines were then plotted against water temperature and the $\mathrm{x}$-intercept (and associated confidence limits) determined using inverse prediction (Zar, 1996).

\section{Husbandry and monitoring}

Each experimental temperature was maintained using a 10kW heat-chill unit, with flow rate to each tank set at $1.5 \mathrm{~L} \mathrm{~min}^{-1}$. Temperature was recorded using StowAway TidbiT temperature loggers (Onset Computer Corporation, Massachusetts) in each system. Animals were fed daily to satiation on a broodstock conditioning diet (Adam and Amos Abalone Foods Pty Ltd, South Australia). Photoperiod was maintained at 12L:12D starting at $06: 00 \mathrm{~h}$ and light intensity at the bottom of the tanks (when filled) was 90-100 Lux. 


\section{Histology}

Following determination of the VGI, abalones were shucked, weighed and the distance from the anterior (i.e. tip) of the conical appendage to the apex of the visceral spire was measured and the mid-point calculated (similar to that illustrated in Ault, 1984 except that posterior measurement was to the apex of visceral spire not the base of the conical appendage). A transverse cut was made at the mid-point and the anterior section fixed in Formaldehyde Acetic Acid Calcium Chloride (FAACC). Gonad samples were embedded in wax, sectioned transversely at $6 \mu \mathrm{m}$ and stained using Mayer's Haematoxylin and Young's Eosin.

\section{Calculation of the Modified Gonad Bulk Index (MGBI) and measurement of oocytes}

Images of conical appendage sections were captured using Leica IM50 software. The cross-sectional areas of the conical appendage $\left(\mathrm{A}_{\mathrm{T}}\right)$, and digestive gland $\left(\mathrm{A}_{\mathrm{DG}}\right)$ were calculated using SigmaScan Pro 5.0. The two area measurements and the length (L) of the conical appendage were used to derive the EGV according to Lleonart's (1992) formula:

$$
E G V=\frac{A_{T} L}{6}\left(8-\left(\sqrt{\frac{A_{D G}}{A_{T}}}+1\right)^{3}\right)
$$

An assumption of the EGV is that the conical appendage consists of two cones; the smaller, inner cone is the digestive gland, and the remaining volume in the larger, outer cone is the gonad (see Ault, 1984 for explanatory diagram). Given that the volume of a right circular cone equals $1 / 3$ base area $x$ length, it is possible to estimate gonad volume from the total area of the conical appendage minus the area occupied by the digestive gland. The EGV and shucked wet weight (WW) of each animal were then used to calculate its MGBI according to the formula MGBI $=\mathrm{EGV} / \mathrm{WW}$.

For the measurement of oocytes, one hundred oocytes with a distinct nucleus (including polygonal oocytes) were traced for each female. As a precaution against heterogeneity of development within the ovary, the oocytes were measured along a transect through the center of the section. The image analysis software was set to record different area and diameter $(\varnothing)$ measurements defined as follows: absolute oocyte area $\left(\mathrm{OA}_{\mathrm{abs}}\right)$, the area inside the perimeter of the oocyte; maximum diameter $\left(\max _{\varnothing}\right)$, the greatest uninterrupted distance inside the perimeter of the oocyte and the minimum diameter $\left(\min _{\varnothing}\right)$, the greatest distance perpendicular to the $\max _{\varnothing}$. Other measurements derived from these included the standardized diameter $\left(\operatorname{stand}_{\varnothing}=\left(\min _{\varnothing}+\max _{\varnothing}\right) / 2\right)$, minimum radius $\left(\min _{\mathrm{r}}=\min _{\varnothing} / 2\right)$, maximum radius $\left(\max _{\mathrm{r}}=\min _{\varnothing} / 2\right)$ and mean radius $\left(\operatorname{mean}_{\mathrm{r}}=\left(\min _{\mathrm{r}}+\right.\right.$ $\left.\max _{\mathrm{r}}\right) / 2$ ).

Prior to calculating oocyte volume, it was necessary to establish which of the two estimates (spherical volume, $\mathrm{SV}=4 / 3 . \pi .\left(\text { mean }_{\mathrm{r}}\right)^{3}$; or ellipsoid volume, $\mathrm{EV}=$ $\left.4 / 3 . \pi .\left(\min _{\mathrm{r}}\right)^{2} \cdot \max _{\mathrm{r}}\right)$ was the most appropriate to use. The first step in this process was to determine if oocyte shape varied, as SV estimates are most accurate when oocytes are round. This was achieved by calculating the oocyte diameter ratio (ODR $\left.=\min _{\varnothing} / \max _{\varnothing}\right)$ of 100 oocytes from 10 randomly selected females of each species and plotting these values against $\min _{\varnothing}$. The next step was to ascertain whether estimated area $\left(\mathrm{OA}_{\text {est }}=\pi \cdot \min _{\mathrm{r}} \cdot \max _{\mathrm{r}}\right)$ approximated the absolute area $\left(\mathrm{OA}_{\mathrm{abs}}\right)$ as the two radii used to generate $\mathrm{OA}_{\text {est }}$ would also be used to calculate oocyte volume. Estimated oocyte area was calculated using the formula for the area of an ellipse, rather than that for a circle as the former takes into account variable radii, whereas the latter does not. In each species, values of $\mathrm{OA}_{\mathrm{abs}}$ and $\mathrm{OA}_{\text {est }}$ were calculated for each of the oocytes in the data sets used above, plotted against $\min _{\varnothing}$ and a curve fitted. Regression analyses between $\min _{\varnothing}, \sqrt{ } \mathrm{OA}_{\mathrm{abs}}$ and $\sqrt{O A}_{\text {est }}$ were run to determine the residual mean square $\left(\mathrm{MS}_{\text {residual }}\right)$ for each relationship, $\mathrm{MS}_{\text {residual }}$ being the 
best criterion of fit when dealing with non-linear data (Quinn and Keogh, 2002).

Correlation analyses were run on $\sqrt{O A}_{\text {abs }}$ versus $\sqrt{ } \mathrm{OA}_{\text {est }}$ for each species to establish if $\mathrm{OA}_{\text {est }}$ approximated $\mathrm{OA}_{\mathrm{abs}}$. The final step in the validation process was to compare and contrast oocyte volume estimates derived using different volume formulae (SV or EV). Both SV and EV were calculated from the same data sets as used previously, plotted against $\min _{\varnothing}$ and a curve fitted. Estimates of SV and EV were cube root transformed and the $\mathrm{MS}_{\text {residual }}$ determined from the regressions between each variable and $\min _{\varnothing}$, with a low $\mathrm{MS}_{\text {residual }}$ indicating a better fit and less variability.

Individual oocytes were not staged during this study and so we were not able to determine if potential changes in shape correlated with particular oocyte stages. However, a data set (based on 7218 oocyte observations) on stage and size frequency of oocytes from wild-caught blacklip abalone from southern Tasmania (L. Gurney, unpublished data) enabled a comparison of changes in oocyte shape and stage relative to $\min _{\varnothing}$.

\section{Contingency table analysis}

Oocyte size frequency data (derived from 100 oocyte measurements per ovary) for all females at each sampling time were used to construct a ( $\mathrm{R} \times \mathrm{C}$ ) contingency table, where $\mathrm{R}$ is the number of sampling times and $\mathrm{C}$ is the number of oocyte size classes (Grant and Tyler, 1983b). Given that all females at each temperature and each sampling time were held under identical conditions, we assumed that they were at the same stage of development when sampled (this was later confirmed by running ANOVA on the oocyte volume data). Thus, the expected frequency $\left(e_{i j}\right)$ at each point was calculated as $e_{i j}=\left(R_{i} X\right.$ $\left.C_{j}\right) / n$, where $R_{i}$ is the total number of oocytes in the $i^{\text {th }}$ size class summed over all individuals, $C_{j}$ is the total number of oocytes measured at the $\mathrm{j}^{\text {th }}$ sampling point and $\mathrm{n}$ is the total number of oocytes measured. Observed $\left(\mathrm{o}_{\mathrm{ij}}\right)$ and expected oocyte volume frequencies were used to calculate the $\chi^{2}$ statistic, according to the formula $\chi^{2}=\sum\left(\left(\mathrm{o}_{\mathrm{ij}}-\mathrm{eij}\right)^{2} /\left(\mathrm{e}_{\mathrm{ij}}\right)\right)$, with $(r-1)(c-1)$ degrees of freedom. Tables of standardized residuals for each temperature group were generated by dividing the residual $r_{i j}\left(\right.$ where $\left.r_{i j}=\left(o_{i j}-e i j\right) /\left(e_{i j}\right)^{0.5}\right)$ by the expected variance $\mathrm{v}_{\mathrm{ij}}\left(\right.$ where $\left.\mathrm{v}_{\mathrm{ij}}=\left(1-\left(\mathrm{r}_{\mathrm{i}} / \mathrm{n}\right)\right) \times\left(1-\left(\mathrm{c}_{\mathrm{j}} / \mathrm{n}\right)\right)\right)$ for all combinations of conditioning interval and size class.

\section{Results}

\section{Increase in VGI and MGBI relative to temperature and conditioning interval}

Within each species and temperature group, the increase in VGI relative to conditioning time was not significantly different between males and females, and VGI data for both sexes were pooled. The mean VGI increased linearly during conditioning in both species $\left(r^{2}=0.58-0.73\right.$ and $0.41-0.74$ for blacklips and greenlips, respectively) with the rate of change in VGI proportional to temperature (Figs 1a and 1b).

The increase in MGBI relative to conditioning time was not significantly different between male and female blacklips or greenlips except for those greenlips held at $16^{\circ} \mathrm{C}$ and $18^{\circ} \mathrm{C}$. Despite this (and in order to maximize sample size), sex was pooled within species for this analysis. The mean MGBI increased linearly during conditioning in both species (Fig. 2) with values ranging from 5-68 $\mathrm{mm}^{3} \mathrm{~g}^{-1}$ and $5-58 \mathrm{~mm}^{3} \mathrm{~g}^{-1}$ for blacklips and greenlips, respectively. The low $\mathrm{r}^{2}$ values for the regressions between MGBI and shucked weight for blacklip (0.02) and greenlip abalone (0.01) confirm that MGBI is a size independent measure of gonad bulk in these species. 
Increase in oocyte size relative to temperature and conditioning interval

The increase in oocyte standardized diameter $\left(\operatorname{stand}_{\varnothing}\right)$ and absolute oocyte area $\left(\mathrm{OA}_{\mathrm{abs}}\right)$ was related to temperature and conditioning time in both species. Mean values of the stand $\varnothing$ and $\mathrm{OA}_{\mathrm{abs}}$ for blacklips ranged from 59-143 $\mu \mathrm{m}$ and $34-143 \times 10^{2} \mu \mathrm{m}^{2}$, respectively. Corresponding values for greenlips were $51-160 \mu \mathrm{m}$ and $27-172 \times 10^{2} \mu \mathrm{m}^{2}$, respectively.

The oocyte diameter ratio (ODR) of oocytes from both species was highly variable in oocytes with a $\min _{\varnothing}<90 \mu \mathrm{m}$ (Figs $3 \mathrm{a}-\mathrm{b}$ ). Above $90 \mu \mathrm{m}$, ODR increased proportionally with $\min _{\varnothing}$, indicating a transition in oocyte shape from elliptical to round with increasing oocyte size. From Fig. 3c, it can be seen that 100\% vitellogenesis occurs in blacklip oocytes $>90 \mu \mathrm{m}$ (L. Gurney, unpublished data), while Fig. 3d shows that the size frequency histogram for greenlip oocytes (this study) is similar in form.

The decision to use EV rather than SV to calculate oocyte volume was based on oocyte shape, which in turn dictated which radii values were used. High variability in ODR meant that few oocytes were perfectly round. Hence, oocyte area and volume (SV) would be over-estimated if the mean of the two radii $\left(\right.$ mean $\left._{\mathrm{r}}\right)$ was used. By contrast, the high correlation between $\mathrm{OA}_{\text {est }}\left(=\pi \cdot \min _{\mathrm{r}} \cdot \mathrm{max}_{\mathrm{r}}\right)$ and absolute oocyte area (from image analysis software) in both species ( $\mathrm{r}=0.993$ and $\mathrm{r}=0.995$ for blacklips and greenlips, respectively) suggests that using $\min _{\mathrm{r}}$ and $\max _{\mathrm{r}}$ to calculate $\mathrm{EV}$ would produce a more accurate estimate of oocyte volume. The greater variability in SV than EV for a given minimum oocyte diameter (as indicated by the greater $\mathrm{MS}_{\text {residual }}$ for $\mathrm{SV}$ than $\mathrm{EV}$, Table 1) is further evidence that $\mathrm{EV}$ provides a better estimate of oocyte volume than SV.

Oocyte volume increased as temperature and conditioning time increased (Figs $4 \mathrm{a}$ and $4 \mathrm{~b})$ with mean oocyte volume ranging from $18-140 \times 10^{4} \mu \mathrm{m}^{3}$ in blacklips and 14-184 $\mathrm{x}$ $10^{4} \mu \mathrm{m}^{3}$ in greenlips.

Estimation of the BZP for gonadal development

The $\mathrm{r}^{2}$ values for the daily rate of increase in VGI, MGBI and oocyte volume (OV) with temperature were 0.98, 0.90 and 0.99 for blacklips (BL, Figs. 5a-c) and 0.99, 0.99 and 0.99 for greenlips (GL, Figs. 5d-f), respectively. BZP estimates derived from the VGI and $\mathrm{OV}$ were similar for $\mathrm{BL}\left(7.8^{\circ} \mathrm{C}\right.$ and $\left.7.6^{\circ} \mathrm{C}\right)$ and $\mathrm{GL}\left(6.9^{\circ} \mathrm{C}\right.$ and $\left.6.8^{\circ} \mathrm{C}\right)$ but were lower for MGBI $\left(\mathrm{BL}=6.0^{\circ} \mathrm{C} ; \mathrm{GL}=5.7^{\circ} \mathrm{C}\right)$. In both species, the most robust estimate of the BZP was derived from the VGI, as evident by the narrower confidence intervals for this variable (Table 2).

\section{Contingency table analysis of oocyte volume frequency}

There were significant differences between the observed and expected frequencies of oocytes in each volume class across the range of EAT conditioning intervals (calculated using the BZP estimates of $7.8^{\circ} \mathrm{C}$ and $6.9^{\circ} \mathrm{C}$ for blacklips and greenlips, respectively) and temperature treatments for blacklip and greenlip abalone $\left(\chi^{2}=254-1281, p<0.001\right)$. Tables 3 and 4 show the standardized residuals for each oocyte volume class against conditioning interval at each experimental temperature for blacklip and greenlip abalone, respectively. The shift in positive residuals from top left to bottom right (i.e. the increase in volume of a cohort of oocytes over time) occurred in a similar fashion in each species and temperature group. 


\section{Discussion}

\section{Gonad development}

In blacklip and greenlip abalone, estimates of the BZP for gonad development derived from the VGI (BZP $\left.{ }_{V G I}\right)$ and oocyte volume $\left(\mathrm{BZP}_{\mathrm{OV}}\right)$ were almost identical, while estimates calculated from the MGBI (BZP $\mathrm{PGBI}_{\mathrm{MG}}$ ) were $1.1-1.8^{\circ} \mathrm{C}$ lower. For ease of comparison between species, the BZP values referred to in the remainder of the discussion are the $\mathrm{BZP}_{\mathrm{VGI}}$ estimates. In the case of $H$. rubra this figure was $7.8^{\circ} \mathrm{C}$, which is similar to that reported for $H$. discus hannai $\left(7.6^{\circ} \mathrm{C}\right.$; Kikuchi and Uki, 1974a). The BZP estimate for $H$. laevigata $\left(6.9^{\circ} \mathrm{C}\right)$ is comparable to that of $\mathrm{H}$. discus discus $\left(5.3^{\circ} \mathrm{C}\right.$; Kikuchi and Uki, $1974 \mathrm{~b}), \mathrm{H}$. australis and $\mathrm{H}$. iris $\left(5.0^{\circ} \mathrm{C}\right.$ and $6.2^{\circ} \mathrm{C}$, respectively; Kabir, 2001).

Unlike the situation off the coast of Japan for $H$. discus hannai and $H$. discus discus (Kikuchi and Uki, 1974a,b), minimum monthly water temperatures experienced by blacklip and greenlip abalone in southern Australian waters do not fall below their BZP. Hence, gonad growth is possible throughout the year, with at least part of the population always reproductively mature (Shepherd and Laws, 1974; McShane et al., 1986; Wells and Mulvay, 1992). In theory, water temperatures during summer/autumn (when the differential between the BZP and ambient temperature is greatest) should promote faster gonad growth than in winter/spring. However, in some cases, high summer water temperatures (e.g. $>22^{\circ} \mathrm{C}$ ) experienced by blacklip and greenlip abalone may stress some (or all) individuals, resulting in gonad development being "deferred" until water temperature fall backs within the preferred range. This, in conjunction with seasonal variations in feed availability and other environmental factors, may explain the presence of mature animals in wild populations at any time of the year.

In mature $H$. rubra and $H$. laevigata, the gonad covers not only the digestive gland, but most of the stomach as well (pers. obs.). Indeed, Lleonart (1992) showed that in mature $H$. laevigata, just $24 \%$ of the total volume of the gonad resides in the conical appendage. This is in contrast to the findings of Tutschulte and Connell (1981), who stated that most of the gonadal tissue is contained in the conical appendage when referring to $H$. corrugata, $H$. fulgens and $H$. sorenseni. While the proportion of gonadal tissue in the conical appendage may vary between species, the effectiveness of the MGBI as a measure of gonad growth is not diminished (at least within species), providing the rate of growth is consistent across the entire gonad. In light of the small volume of gonad in the conical appendage of $H$. rubra and $H$. laevigata, we took a slightly different measure of the conical appendage compared to previous studies on gonad volume. The apex of the visceral spire, rather than the base of the conical appendage (see Ault, 1984), was used as the posterior measurement point. Hence, the EGV and MGBI values are greater than they would have been with the standard method.

The MGBI estimates for blacklips $\left(5-68 \mathrm{~mm}^{3} \mathrm{~g}^{-1}\right)$ and greenlips $\left(5-58 \mathrm{~mm}^{3} \mathrm{~g}^{-1}\right)$ obtained here were similar or slightly lower than values for other species (Tutschulte and Connell, 1981; Ault, 1985; Wood and Buxton, 1996; Capinpin et al., 1998). By contrast, our upper MGBI estimate for greenlips is greater than that reported by Lleonart (1992) since he used whole body weight, rather than shucked weight in the estimates. While we found small differences in maximum MGBI between $H$. rubra and $H$. laevigata, Tutschulte and Connell (1981) reported much larger differences for Californian abalones, the maximum value for $H$. corrugata being $110 \mathrm{~mm}^{3} \mathrm{~g}^{-1}$ as opposed to $180 \mathrm{~mm}^{3} \mathrm{~g}^{-1}$ for $H$. sorenseni. Clearly, the volume occupied by the gonad, relative to the shucked weight of the animal differs between species. This in turn leads to species differences in both overall and weight-specific fecundity, bearing in mind that oocyte size varies between species (Sawatpeera et al., 2001). 
The degree to which the EGV correlates with potential fecundity (i.e. egg counts from ovarian tissue) was not examined here as we believe that this measure of fecundity tends to overestimate the number of eggs that are actually spawned. The extent of the overestimate is dependent on the degree of partial spawning, absorption or necrosis of oocytes and/or the presence of multiple cohorts of oocytes in some species (e.g. Newman, 1967; Jebreen et al., 2000).

\section{Oocyte development}

The standardized diameter, area and volume of oocytes of $H$. rubra and $H$. laevigata increased proportionally with temperature and conditioning interval. The standardized diameters of oocytes recorded here were within the range of values previously reported for these species (Harrison and Grant, 1971; Shepherd and Laws, 1974; McShane et al., 1986; Lleonart, 1992), while oocyte areas were similar to those of $H$. iris and $H$. australis (Wilson and Schiel, 1995; Kabir, 2001).

Only Hahn (1994) has previously recorded oocyte volume for abalone. He calculated the maximum oocyte volume at $9.5 \times 10^{4} \mu^{3}$ for $H$. discus hannai using the formula for the volume of a sphere, which equates to a standardized diameter of $122 \mu \mathrm{m}$. This was less than the maximum oocyte diameters for $H$. rubra and $H$. laevigata reported here $(143 \mu \mathrm{m}$ and $160 \mu \mathrm{m}$, respectively). We calculated oocyte volume based on an ellipsoid shape and the data show that volume increases linearly during conditioning, whereas Hahn's (1994) work, using spherical volume, suggests an exponential increase. Hahn (1994) argued that conventional methods used to express oocyte size, such as oocyte diameter, resulted in over-emphasis of smaller oocytes and under-emphasis of larger oocytes. He used the lesser diameter of stalked oocytes and the mean diameter of polygonal or round oocytes when calculating their volume. However, small, stalked oocytes are teardrop (almost elliptical) in shape, so using the lesser diameter of these oocytes under-estimated volume. Furthermore, using the mean diameter of the larger polygonal oocytes when calculating their volume leads to over-estimates as they are not perfectly round. By using the formula for the volume of an ellipsoid, we minimized both sources of error.

Comparing patterns in standardized residuals of blacklip and greenlip oocytes during conditioning with similar data from other haliotid studies is complicated by a number of factors. Both Lleonart (1992) and Moss (1998) expressed oocyte size as diameter, Kabir (2001) presented oocyte area, while Hahn (1994) calculated oocyte volume, using a different methodology. Furthermore, the range of oocyte size classes and sampling frequencies varied between the studies. If sampling is infrequent or oocyte size ranges too broad, this reduces the degrees of freedom for significance testing and the number of standardized residuals in the table. Hence, the difference between some residuals may not be significant, masking fine scale changes in oocyte development. We recommend that oocyte volume size classes be presented in geometric progression, as the rate of change in volume is much greater in large oocytes than in small ones.

The means of expressing conditioning interval is also important in presenting data on the dynamics of gonad or oocyte size of haliotids. Since each species has a different BZP, the EAT interval, rather than conditioning time (in days), should be used. Hahn (1994) identified this issue and related the EAT interval to oocyte volume and to tables of standardized residuals. However, Kabir (2001) presented conditioning times in days for $H$. iris and $H$. australis, but since he also determined the BZP's, the EAT conditioning intervals can also be calculated. Clearly, sampling frequency, the number of oocyte size categories and the means by which conditioning interval and oocyte size are expressed need to be sufficient to allow comparisons between such studies in future. 


\section{Conclusions}

This study showed that the rate of gonad development in both blacklip and greenlip abalone was dependent on the cumulative difference between the holding temperature and the BZP. The BZP for gonadal development of blacklip abalone was $7.8^{\circ} \mathrm{C}$ and that of greenlip abalone was $6.9^{\circ} \mathrm{C}$. The ODR during early oogenesis of both species was highly variable, but above a minimum diameter of $90 \mu \mathrm{m}$ oocyte shape was less variable and ODR approached 1. The use of the formula for the volume of an ellipsoid rather than of a sphere provided the more accurate estimate of actual oocyte volume. We recommend that future works on contingency table analysis of oocyte size frequency in abalone use ellipsoid volume and pay particular attention to sampling frequency, categorization of oocyte size classes and the means of expressing conditioning time (using EAT degree days).

\section{Acknowledgements}

This project was funded by the FRDC project number 2000/204 (managed by the Abalone Aquaculture Subprogram) awarded to A.J.R. We thank Charles Mason of Furneaux Aquaculture for collection of abalone broodstock. Joel Scanlon of Adam and Amos Abalone Feeds Pty Ltd kindly donated broodstock feed for the experiment. Assistance from Alan Beech and Bob Hodgson during the construction of the experimental system was greatly appreciated. Craig Mundy and Leigh Gurney provided statistical advice and assistance with data manipulation, respectively and they with Chris Burke, provided constructive criticism on the manuscript.

\section{References}

Ault, J.S., Some quantitative aspects of reproduction and growth of the red abalone, Haliotis rufescens Swainson. Journal of the World Aquaculture Society, 16 (1985) 398-425.

Capinpin, E.C., Encena, V.C. and Bayona, N.C., Studies on the reproductive biology of the Donkey's ear abalone, Haliotis asinina Linné. Aquaculture, 166 (1998) 141-150.

Clark, F.N., Maturity of the Californian sardine (Sardina caerulea), determined by ova diameter measurements. Div. Fish Game Calif., Fish Bull., 42 (1934) 1-49.

Grant, A. and Tyler, P.A., The analysis of data in studies of invertebrate reproduction. I. Introduction and statistical analysis of gonad indices and maturity indices. Int. J. Invertebr. Reprod., 6 (1983a) 259-269.

Grant, A. and Tyler, P.A., The analysis of data in studies of invertebrate reproduction. II. The analysis of oocyte size/frequency data, and comparison of different types of data. Int. J. Invertebr. Reprod., 6 (1983b) 271-283.

Grubert, M.A. and Ritar, A.J., Abalone broodstock conditioning system at TAFI MRL. Austasia Aquaculture, 16 (2002) 29-36

Hahn, K.O., Gonad reproductive cycles. In: Hahn, K.O. (ed.), Handbook of Culture of Abalone and Other Marine Gastropods, CRC Press, Boca Raton, 1989, pp. 13-39.

Hahn, K.O., Gametogenic cycle of the Japanese abalone (ezoawabi), Haliotis discus hannai, during conditioning with effective accumulative temperature. Aquaculture, 122 (1994) 227-236.

Harrison, A.J. and Grant, J.F., Progress in abalone research. Tasmanian Fish. Res., 5 (1971) 1-10. 
Jebreen, E.J., Counihan, R.T., Fielder, D.R. and Degnan, B.M., Synchronous oogenesis during the semilunar spawning cycle of the tropical abalone Haliotis asinina. J. Shellfish Res., 19 (2000) 845-851.

Kabir, N.M.J., Environmental, chemical and hormonal regulation of reproduction in two commercially important New Zealand abalone, Haliotis iris and H. australis. $\mathrm{PhD}$ dissertation, Dunedin, University of Otago, 2001, 236 pp.

Kikuchi, S. and Uki, N., Technical study of artificial spawning of abalone, genus Haliotis I. Relationship between water temperature and advancing sexual maturity of Haliotis discus hannai Ino. Bull. Tohoku Reg. Fish. Res. Lab., 33 (1974a) 69-78 (in Japanese with English abstract).

Kikuchi, S. and Uki, N., Technical study of artificial spawning of abalone, genus Haliotis V. Relationship between water temperature and advancing sexual maturity of Haliotis discus Reeve. Bull. Tohoku Reg. Fish. Res. Lab., 34 (1974b) 77-85 (in Japanese with English abstract).

Lleonart, M., A gonad conditioning study of the greenlip abalone Haliotis laevigata. MS thesis, Launceston, University of Tasmania, 1992, $162 \mathrm{pp}$.

McShane, P.E., Beinssen, K.H.H., Smith, M.G., O'Conner, S. and Hickman, N.J., Reproductive biology of blacklip abalone Haliotis ruber Leach from four Victorian populations. Department of Conservation Forests \& Lands, Fisheries and Wildlife Service, Technical Report No. 55, 1986, 13 pp.

Moss, G.A., Effect of temperature on the breeding cycle and spawning success of the New Zealand abalone, Haliotis australis. N. Z. J. Mar. Freshwat. Res., 32 (1998) 139146.

Newman, G.C., Reproduction of the South African abalone Haliotis midae. Investl Rep. Div. Sea Fish. S. Afr., 64 (1967) 1-24.

Quinn, G.P. and Keogh, M.J., Experimental design and data analysis for biologists. Cambridge University Press, Cambridge, 2002, 537 pp.

Sawatpeera, S., Upatham, E.S., Kruatrachue, M., Chitramvong, Y.P., Songchaeng, P., Pumthong, T. and Nugranad, J., Larval development in Haliotis asinina Linnaeus. J. Shellfish Res., 20 (2001) 593-601.

Shepherd, S.A. and Laws, H.M., Studies on Southern Australian abalone (Genus Haliotis) II. Reproduction of five species. Aust. J. Mar. Freshwat. Res., 24 (1974) 49-62.

Thompson, W.F., A preliminary report on the life-history of the halibut. British Columbia. Comm. Fish. Rept. for 1914, (1915) 76-99.

Tutschulte, T. and Connell, J.H., Reproductive biology of three species of abalones (Haliotis) in Southern California. Veliger, 23 (1981) 195-206.

Wells, F.E. and Mulvay, P., Reproduction and growth of the greenlip abalone Haliotis laevigata on the south coast of Western Australia. Western Australian Department of Fisheries, Perth, 1992, 117 pp.

Wilson, N.H.F. and Schiel, D.R., Reproduction in two species of abalone (Haliotis iris and H. australis) in southern New Zealand. Mar. Freshwater Res., 46 (1995) 629-637.

Wood, A.D. and Buxton, C.D., Aspects of the biology of the abalone Haliotis midae (Linné, 1758) on the east coast of South Africa. 2. Reproduction. S. Afr. J. Mar. Sci., 17 (1996) 69-78.

Zar, J.D., Biostatistical analysis, 3rd Edition. Prentice Hall, New York, 1996, 659 pp. 
Table 1. Power functions describing the relationships between minimum oocyte diameter (x) and absolute area $\left(\mathrm{OA}_{\mathrm{abs}}\right)$, estimated area $\left(\mathrm{OA}_{\text {est }}\right)$, spherical volume $(\mathrm{SV})$ and ellipsoid volume (EV) in blacklip and greenlip abalone. The value of the mean square residual $\left(\mathrm{MS}_{\text {residual }}\right)$ is proportional to the degree of variability in the data.

\begin{tabular}{cccccc}
\hline & \multicolumn{2}{c}{ Blacklip } & & \multicolumn{2}{c}{ Greenlip } \\
\cline { 2 - 3 } \cline { 5 - 6 } Variable $(\mathrm{y})$ & Function & $\mathrm{MS}_{\text {residual }}$ & & Function & $\mathrm{MS}_{\text {residual }}$ \\
\hline $\mathrm{OA}_{\mathrm{abs}}$ & $=2.381 \mathrm{x}^{1.824}$ & 122.3 & & $=2.001 \mathrm{x}^{1.852}$ & 114.1 \\
$\mathrm{OA}_{\mathrm{est}}$ & $=2.220 \mathrm{x}^{1.864}$ & 118.5 & & $=1.924 \mathrm{x}^{1.885}$ & 94.5 \\
$\mathrm{SV}$ & $=3.513 \mathrm{x}^{2.740}$ & 165.5 & & $=2.656 \mathrm{x}^{2.782}$ & 128.5 \\
$\mathrm{EV}$ & $=1.482 \mathrm{x}^{2.865}$ & 36.5 & & $=1.283 \mathrm{x}^{2.886}$ & 30.2 \\
\hline
\end{tabular}

Table 2. Upper and lower 95\% confidence intervals (CI) for BZP estimates (in ${ }^{\circ} \mathrm{C}$ ) derived from the Visual Gonad Index (VGI), Modified Gonad Bulk Index (MGBI) and oocyte volume (OV) for blacklip (BL) and greenlip (GL) abalone. Dash indicates slope approximated zero, therefore CI's cannot be calculated.

\begin{tabular}{ccccc}
\hline Measure & Species & BZP & Upper 95\% CI & Lower 95\% CI \\
\hline VGI & BL & 7.8 & 9.1 & 2.6 \\
& GL & 6.9 & 9.9 & -1.7 \\
MGBI & BL & 6.0 & - & - \\
& GL & 5.7 & 9.3 & -9.8 \\
OV & BL & 7.6 & 11.0 & -2.2 \\
& GL & 6.8 & 10.6 & -4.6 \\
\hline
\end{tabular}


Table 3. Contingency table of standardized residuals for frequencies of oocyte volume in female blacklip abalone $(\mathrm{n}=$ sample size $)$ at each temperature and conditioning interval.

Positive values (in bold) indicate a greater than expected frequency of oocytes in that size class, whereas the negative values indicate a lower than expected frequency.

\begin{tabular}{|c|c|c|c|c|c|c|c|c|c|c|c|c|}
\hline \multirow[t]{2}{*}{$\mathrm{T}^{\circ} \mathrm{C}$} & \multirow[t]{2}{*}{$\operatorname{EAT}\left({ }^{\circ} \mathrm{C}-\mathrm{d}\right)$} & & \multicolumn{10}{|c|}{ Oocyte volume class $\left(\mu \mathrm{m}^{3} \times 10^{5}\right)$} \\
\hline & & $\mathrm{n}$ & 0.1 & 0.2 & 0.4 & 0.8 & 1.6 & 3.2 & 6.4 & 12.8 & 25.6 & 51.2 \\
\hline \multirow[t]{4}{*}{12} & 0 & 3 & 1.5 & 4.8 & 4.1 & 2.8 & 2.1 & 0.1 & -2.8 & -6.1 & -3.6 & -1.3 \\
\hline & 330 & 3 & 1.0 & 3.4 & 0.3 & -1.8 & -1.7 & -0.3 & 0.0 & 0.1 & 0.5 & -1.5 \\
\hline & 660 & 3 & 0.2 & -2.4 & -0.7 & 0.0 & -0.1 & -0.4 & 1.1 & 2.1 & -0.3 & -0.2 \\
\hline & 990 & 5 & -1.5 & -3.0 & -2.3 & -0.9 & -0.5 & 0.3 & 1.1 & 2.4 & 2.2 & 1.6 \\
\hline \multirow[t]{5}{*}{14} & 0 & 3 & 3.1 & 5.6 & 4.3 & 2.0 & -0.4 & 0.8 & -2.0 & -3.9 & -6.1 & -1.6 \\
\hline & 350 & 3 & 0.4 & 2.1 & 0.5 & 1.2 & 0.1 & 0.2 & -0.3 & -3.0 & -0.7 & 0.6 \\
\hline & 700 & 4 & -0.8 & -2.2 & 0.2 & 1.5 & 0.1 & -0.8 & -0.6 & 0.8 & 0.7 & 0.4 \\
\hline & 1050 & 4 & -0.5 & -2.4 & -2.1 & -2.7 & 1.2 & 0.2 & 1.1 & 3.4 & 1.2 & 0.0 \\
\hline & 1400 & 3 & -1.9 & -2.0 & -2.5 & -1.7 & -1.3 & -0.2 & 1.7 & 1.7 & 4.3 & 0.6 \\
\hline \multirow[t]{7}{*}{16} & 0 & 3 & 4.9 & 5.5 & 7.7 & 7.4 & 0.2 & -0.4 & -1.0 & -6.7 & -8.3 & -3.3 \\
\hline & 360 & 3 & 1.4 & 4.2 & 4.3 & 3.1 & 2.7 & 1.6 & -0.7 & -3.8 & -6.7 & -2.0 \\
\hline & 720 & 3 & 2.5 & 2.2 & 4.6 & 1.4 & 2.9 & 0.5 & -1.4 & -4.8 & -2.4 & -2.5 \\
\hline & 1080 & 3 & 0.7 & 0.5 & 0.6 & 0.3 & 1.8 & 0.0 & -1.0 & 0.0 & -1.0 & -1.5 \\
\hline & 1440 & 4 & -1.5 & -2.0 & -2.0 & -1.0 & -1.3 & 1.1 & 2.4 & 4.0 & -0.6 & -1.3 \\
\hline & 1800 & 5 & -2.1 & -1.0 & -4.1 & -3.0 & -0.5 & 0.0 & 1.4 & 4.2 & 2.3 & -0.1 \\
\hline & 2160 & 6 & -3.0 & -5.2 & -5.6 & -4.1 & -3.3 & -1.9 & -0.5 & 2.8 & 9.8 & 6.8 \\
\hline \multirow[t]{7}{*}{18} & 0 & 3 & 10.0 & 9.5 & 5.5 & 2.0 & 0.9 & 0.9 & 0.0 & -5.2 & -10.0 & -3.6 \\
\hline & 370 & 3 & 1.5 & 2.9 & 3.8 & 5.4 & 3.4 & -0.7 & -0.2 & -3.3 & -6.1 & -2.6 \\
\hline & 740 & 3 & 0.4 & 2.3 & 2.4 & 0.6 & 1.5 & -1.7 & 1.6 & 0.5 & -4.7 & -1.4 \\
\hline & 1110 & 3 & -1.9 & -1.1 & -1.3 & 1.6 & 1.8 & 1.9 & 0.8 & 2.8 & -3.4 & -1.1 \\
\hline & 1480 & 4 & -2.2 & -0.5 & -0.1 & -0.8 & 0.2 & 1.7 & 2.0 & -0.4 & 0.1 & -0.9 \\
\hline & 1850 & 6 & -2.3 & -3.6 & -1.9 & -2.6 & -3.2 & -0.5 & -1.3 & 1.6 & 6.5 & 2.9 \\
\hline & 2220 & 6 & -2.3 & -4.6 & -4.5 & -2.8 & -1.6 & -1.0 & -1.6 & 2.0 & 8.5 & 3.2 \\
\hline
\end{tabular}


Table 4. Contingency table of standardized residuals for frequencies of oocyte volume in female greenlip abalone $(\mathrm{n}=$ sample size $)$ at each temperature and conditioning interval. Positive values (in bold) indicate a greater than expected frequency of oocytes in that size class, whereas the negative values indicate a lower than expected frequency.

\begin{tabular}{|c|c|c|c|c|c|c|c|c|c|c|c|c|}
\hline \multirow[t]{2}{*}{$\mathrm{T}^{\circ} \mathrm{C}$} & \multirow[t]{2}{*}{$\operatorname{EAT}\left({ }^{\circ} \mathrm{C}-\mathrm{d}\right)$} & & \multicolumn{10}{|c|}{ Oocyte volume class $\left(\mu \mathrm{m}^{3} \times 10^{5}\right)$} \\
\hline & & $\mathrm{n}$ & 0.1 & 0.2 & 0.4 & 0.8 & 1.6 & 3.2 & 6.4 & 12.8 & 25.6 & 51.2 \\
\hline \multirow[t]{4}{*}{12} & 0 & 3 & 1.0 & 2.2 & 6.4 & 6.7 & 1.0 & -0.3 & -1.8 & -5.1 & -7.2 & -1.8 \\
\hline & 500 & 4 & 1.2 & 2.0 & 1.4 & -0.3 & 1.0 & -0.3 & -0.4 & -1.6 & -1.5 & -1.3 \\
\hline & 1000 & 4 & -0.5 & -1.4 & -3.5 & -2.4 & -0.3 & 1.4 & 0.8 & 1.6 & 3.4 & 1.4 \\
\hline & 1500 & 3 & -1.8 & -2.9 & -3.8 & -3.3 & -1.9 & -1.0 & 1.3 & 5.1 & 4.8 & 1.7 \\
\hline \multirow[t]{5}{*}{14} & 0 & 3 & 3.3 & 5.5 & 11.2 & 8.2 & 1.8 & -1.0 & -2.1 & -5.8 & -11.2 & -3.2 \\
\hline & 470 & 4 & 2.5 & 1.8 & 1.7 & 2.7 & 2.4 & 2.6 & 0.2 & -2.4 & -5.8 & -0.6 \\
\hline & 940 & 4 & 0.0 & 0.2 & -1.1 & -0.3 & 1.8 & 0.5 & 3.8 & 0.4 & -3.2 & -0.2 \\
\hline & 1410 & 5 & -2.1 & -1.7 & -2.9 & -3.2 & -1.3 & -0.2 & -1.7 & 1.9 & 6.1 & 1.2 \\
\hline & 1880 & 5 & -2.3 & -3.7 & -5.4 & -4.4 & -3.4 & -1.8 & -0.2 & 3.7 & 9.2 & 1.7 \\
\hline \multirow[t]{7}{*}{16} & 0 & 3 & 4.9 & 5.9 & 15.5 & 13.5 & 5.4 & 1.5 & -0.6 & -7.4 & -15.7 & -4.7 \\
\hline & 450 & 3 & 5.7 & 5.0 & 3.8 & 2.9 & 0.9 & 0.8 & 2.3 & -4.7 & -6.9 & 0.3 \\
\hline & 900 & 4 & 1.3 & 3.3 & 1.4 & -0.2 & 3.5 & 3.6 & 1.5 & -2.9 & -2.3 & -2.5 \\
\hline & 1350 & 6 & -1.9 & 0.4 & -1.3 & -0.3 & -1.7 & -0.3 & -0.3 & 2.7 & 0.3 & -0.6 \\
\hline & 1800 & 6 & -1.7 & -2.6 & -2.8 & -2.6 & -1.7 & -1.2 & 1.1 & 3.3 & 3.7 & -1.2 \\
\hline & 2250 & 6 & -1.9 & -3.5 & -4.9 & -3.7 & -1.0 & -0.6 & -1.4 & 4.2 & 4.7 & 1.3 \\
\hline & 2700 & 5 & -2.5 & -4.2 & -4.9 & -4.2 & -2.6 & -2.4 & -1.7 & -0.3 & 8.4 & 5.9 \\
\hline \multirow[t]{7}{*}{18} & 0 & 3 & 5.0 & 5.8 & 12.4 & 11.7 & 3.6 & 0.6 & -1.2 & -6.7 & -14.1 & -3.9 \\
\hline & 440 & 3 & 3.8 & 6.7 & 3.8 & 5.0 & 3.9 & 3.0 & 1.4 & -1.8 & -11.3 & -3.7 \\
\hline & 880 & 4 & 0.1 & 2.8 & 1.1 & 0.3 & 0.1 & 2.7 & 2.4 & -0.5 & -4.1 & -1.2 \\
\hline & 1320 & 4 & -0.8 & -2.7 & -1.3 & -2.7 & -0.9 & -0.3 & 1.9 & 2.9 & 2.1 & -1.6 \\
\hline & 1760 & 6 & -2.4 & -3.2 & -4.4 & -3.6 & -2.0 & -1.5 & -1.8 & 2.3 & 7.9 & 1.2 \\
\hline & 2200 & 3 & -1.8 & -3.6 & -3.7 & -4.3 & -0.6 & -1.8 & -0.6 & 1.9 & 7.0 & 1.4 \\
\hline & 2640 & 3 & -2.2 & -3.8 & -5.2 & -3.7 & -2.6 & -2.2 & -1.9 & -0.1 & 7.9 & 7.7 \\
\hline
\end{tabular}



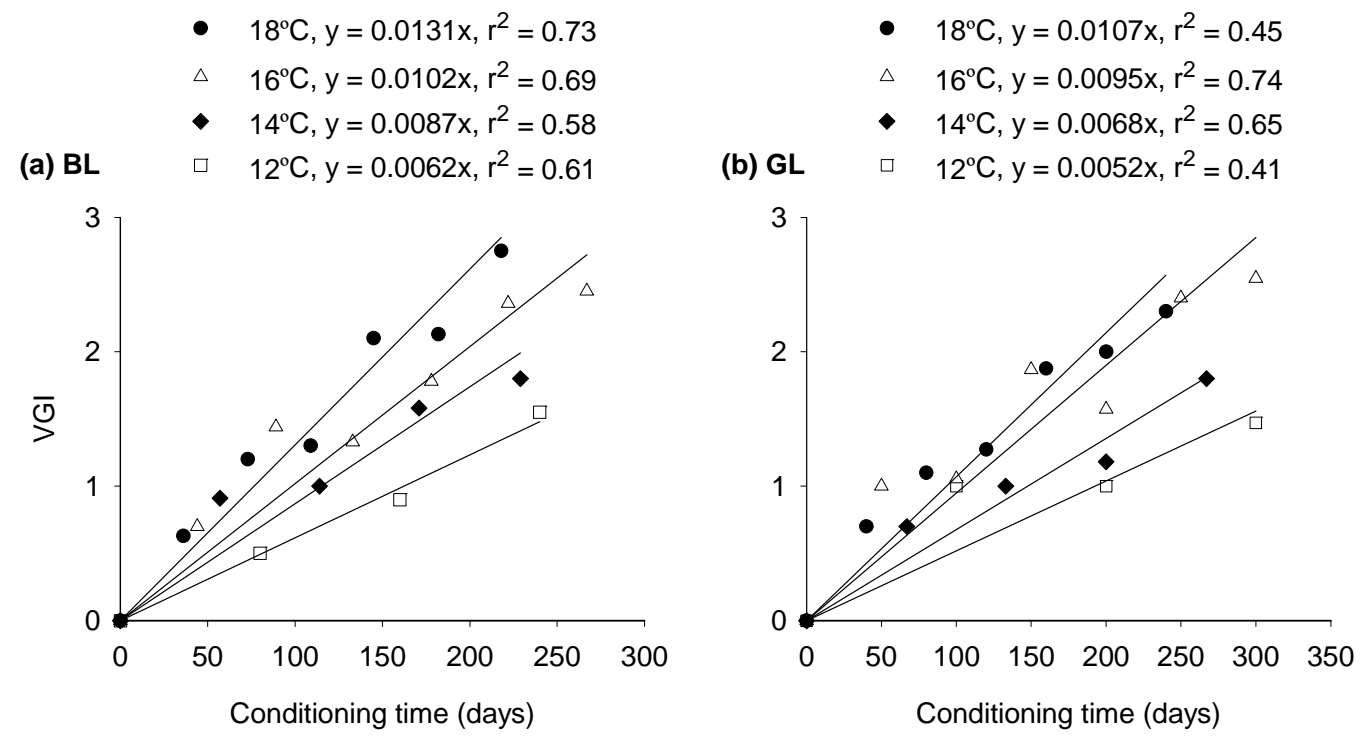

Fig. 1. Increase in mean Visual Gonad Index (VGI) score relative to conditioning time and culture temperature in blacklip (BL, a) and greenlip (GL, b) abalone. Data for males and females within species were pooled.
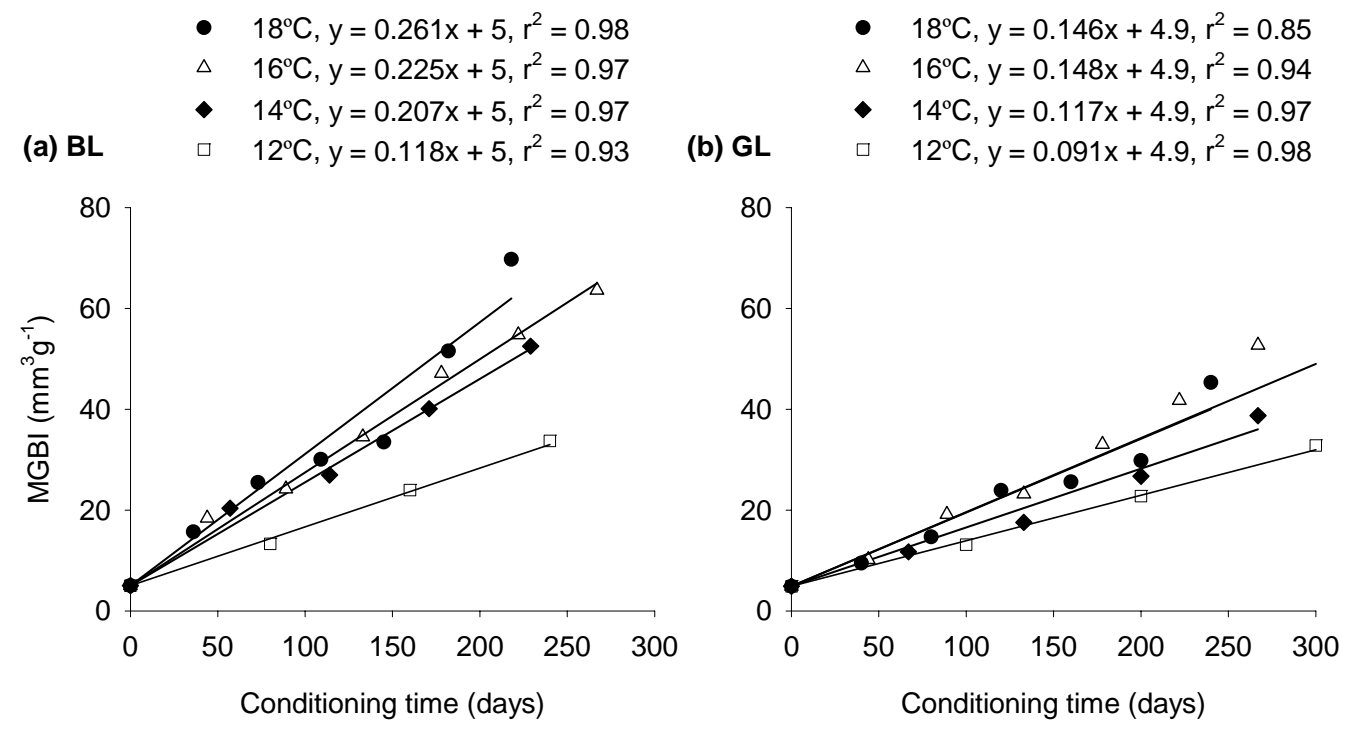

Fig. 2. Increase in Modified Gonad Bulk Index (MGBI) relative to conditioning time and culture temperature in blacklip (BL, a) and greenlip $(\mathrm{GL}, \mathrm{b})$ abalone. Lines for the greenlip $16^{\circ} \mathrm{C}$ and $18^{\circ} \mathrm{C}$ treatments overlap. Data for males and females within species were pooled. 
(a) Blacklip abalone

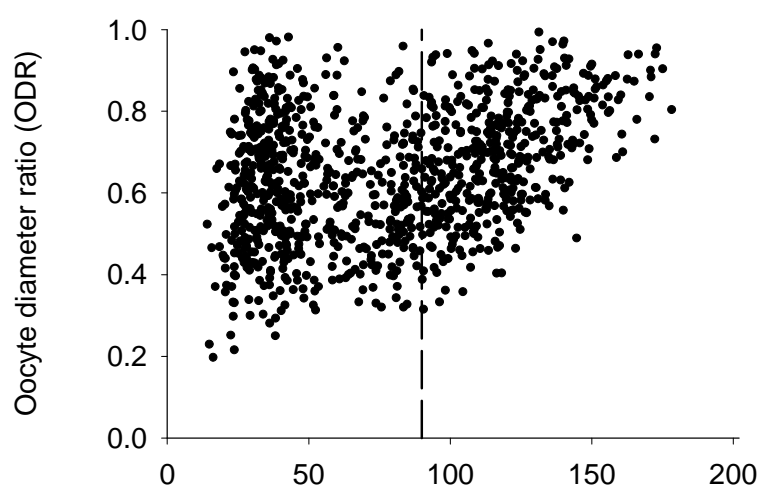

(c) Blacklip abalone (L. Gurney, unpublished) (b) Greenlip abalone

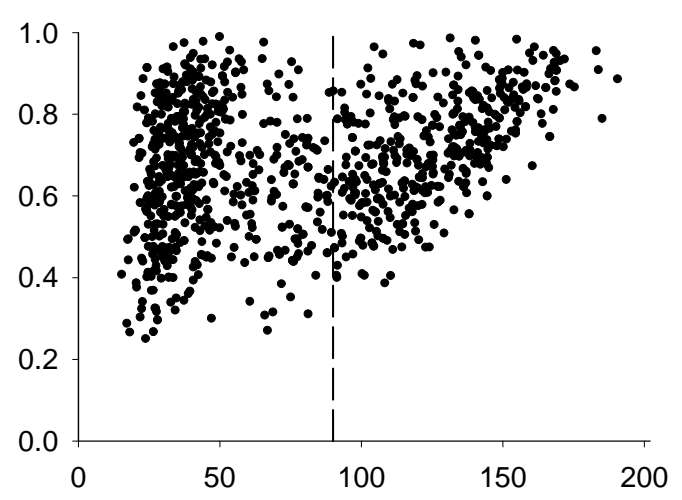

(d) Greenlip abalone (this study)
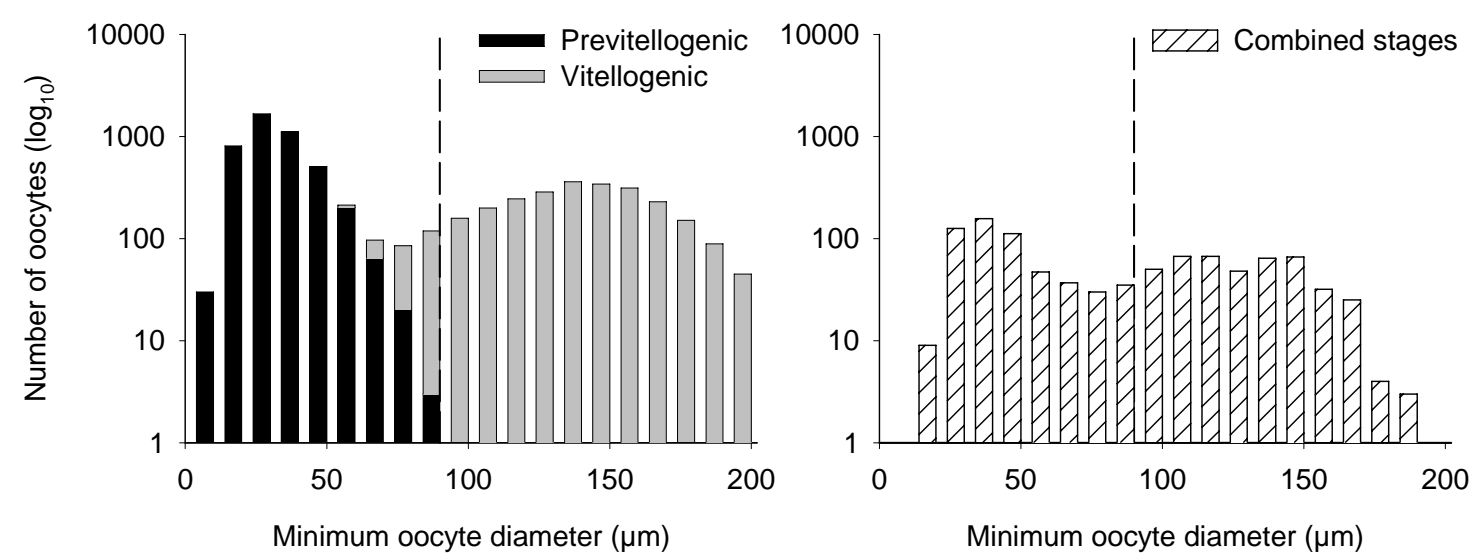

Fig. 3. The relationship between minimum oocyte diameter and Oocyte Diameter Ratio (ODR; minimum diameter / maximum diameter) in (a) blacklip and (b) greenlip abalone as well as stage and size frequency of oocytes in (c) blacklip (from L. Gurney, unpublished) and (d) greenlip abalone (this study). Dashed lines indicates minimum oocyte diameter of $90 \mu \mathrm{m}$. 

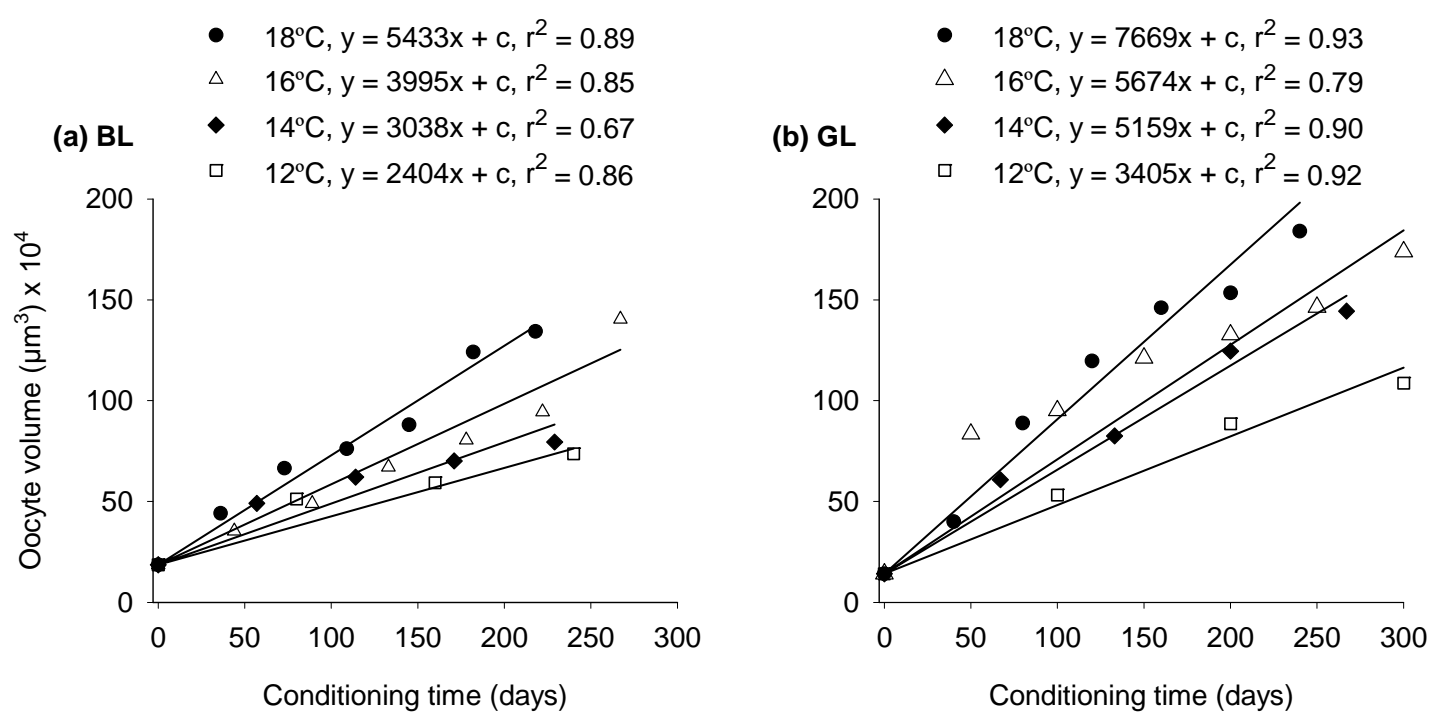

Fig. 4. The relationship between conditioning time (x), culture temperature and oocyte volume (y) in (a) blacklip and (b) greenlip abalone. Values of constant c were $1.86 \times 10^{4}$ and $1.42 \times 10^{4}$ for blacklip (BL) and greenlip (GL) abalone, respectively. 
(a) BL VGI

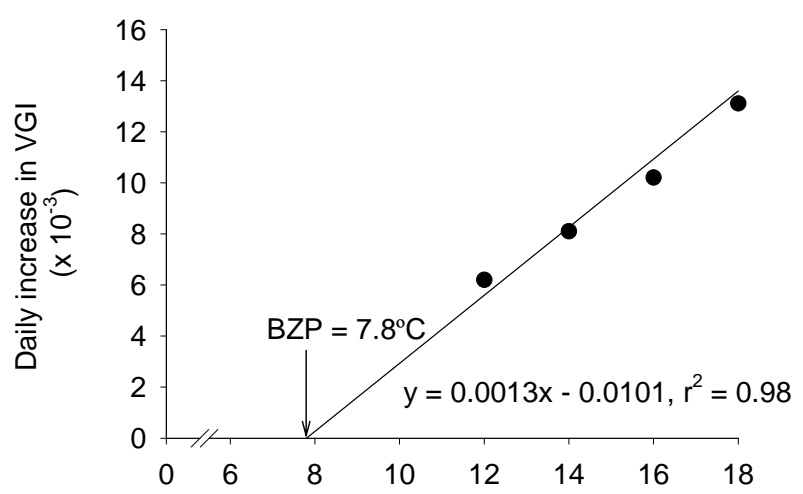

(b) BL MGBI

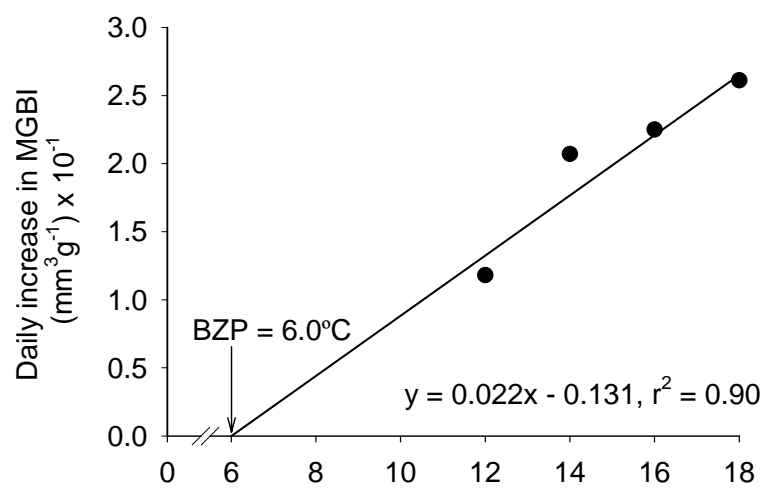

(c) BL OV

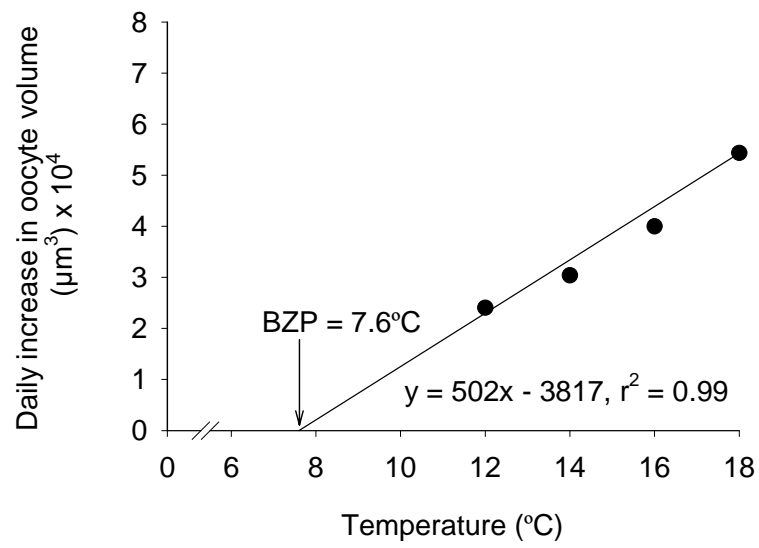

(d) GL VGI

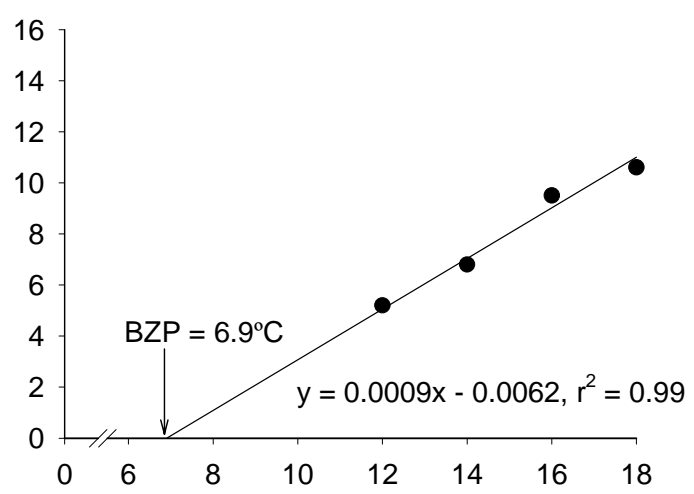

(e) GL MGBI

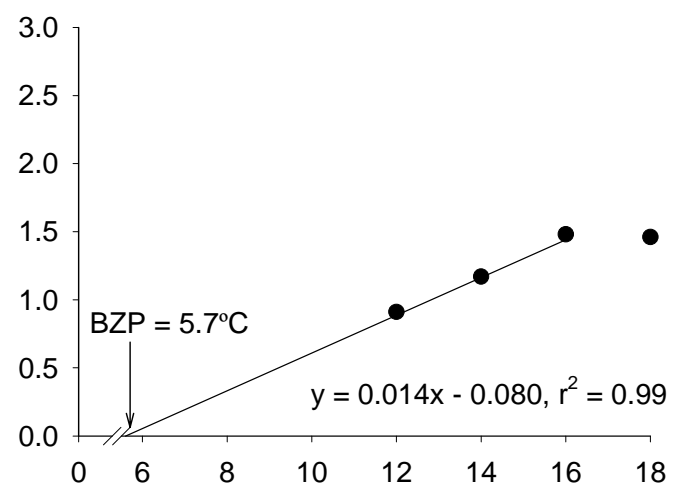

(f) GL OV

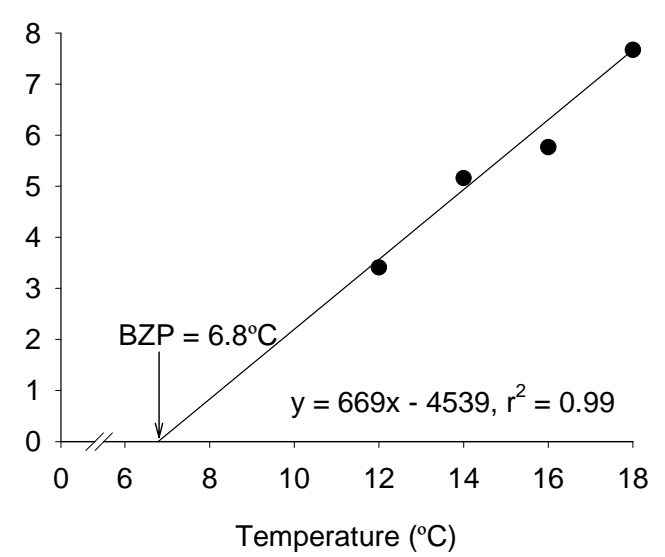

Fig. 5. The relationship between Visual Gonad Index (VGI), Modified Gonad Bulk Index (MGBI), oocyte volume and culture temperature in blacklip (BL, a-c) and greenlip (GL, $\mathrm{d}-\mathrm{f}$ ) abalone. Linear relationship in $5 \mathrm{e}$ did not include the outlier value at $18^{\circ} \mathrm{C}$. 